Rhynchocyon is described. Lanthanotherium is recognized in the faunas for the first time, an interesting addition in view of its occurrence in Europe and North America. The bat material is limited to two humeri. Von Koenigswald's paper deals with three new genora of Miocene primates, two of them placed in the Cercopithecoidea and one in the Oreopithecoidea. The separation of these specimens into new taxa at generic level is questionable and not adequately maintained by the textural description. In the discussion, the author raises a number of interesting issues, but these are not pursued sufficiently to assess their significance.

R. E. F. Leakey presents a paper on two Pleistocone cercopithecoids from Lake Baringo; a new genus of colobid and a new species of baboon. Both are known from well preserved skull and mandible, and these are described in detail with the aid of comparative tables which make the morphological characteristics quite clear. Hooijer reports on the rhinoceroses from a series of Pleistocene sites in East Africa; the bulk of the material comes from the Olduvai succession, with additional specimens from Baringo, Laetolil, Omo, Kanam, Naivasha and Olorgesailie. Skull, mandible and teeth were available, together with a fair quantity of postcranial material which, however, is difficult to identify. Hooijer recognizes only two rhinoceroses in the Pleistocene of East Africa (as in South Africa), and these are Diceros bicornis and Ceratotherium simum, the first a browser and the latter a grazer. This simplicity is admirable and removes much of the confusion in earlier literature when taxa were created on inadequate data.

The volume is the forerunner of what promises to be a very important series of monographs on African fossil mammals.

R. J. G. Savage

\section{PERSONAL PETROLOGY}

\section{Metamorphic Petrology}

Mineralogical and Field Aspects. By Francis J. Turner. (McGraw-Hill International Series in the Earth and Planetary Sciences.) Pp. xi +403 . (McGraw-Hill: New York and Maidenhead, 1968.) \$13.50; 126s.

Purchasens of this book will possess the best text available on metamorphic petrology, perhaps more appropriately sub-titled "An Aspect of Mineral Stability and Regional Occurrence". The use of "aspect" in the singular results from the highly personalized nature of the work and from the admitted biases of the author. It includes several new sections, and substantial revisions of older material from the author's former books, commencing with a section on the regional occurrence of metamorphic rocks, followed by a chapter on metamorphic facies and thermodynamies, then two chapters on theoretical and experimental aspects of mineral stability, three more chapters on metamorphic facies (including discussions of several regions) and finally a section on "Temperature-Pressure-Time Regimes of Regional Metamorphism". Illustrations are clear and generous in numbor; the bibliography to 1966 is excellent, and indexing is comprehensive. Purchasers also acquire one misprint every six pages and a number of erroneous arguments and tendentious statements.

There is much to be said in favour of the concept of this book, combining broad facts of occurrence, details of mineral assemblages, an appraisal of experimental data on metamorphic minerals, a review of the metamorphic facies concept and an attempt to relate metamorphic rocks to crustal processes. It leaves out, however, petrographic and structural properties, all discussion of metasomatism and of the impact of isotope geology on studies of metamorphism, notably those concerning temperatures and time. The absence of discussion of metasomatism and the curt and cursory trcatment of open chemical systems is a serious omission from a book purporting to discuss metamorphic petrology in general.

The first chapter introduces several examples of metamorphic complexes, unfortunately divided into contact and regional, perpetuating thereby the problems which arise from this thermochemically arbitrary division. The examples are well chosen, but the illustrations are weak, containing insufficient detail. The second chapter contains discussions of facies and of thermodynamics which could well be placed elsewhere and critically reconsidered: there is no mention of facies series at this stage. The thermodynamics is too brief and contains misleading simplifications: the section on coupled reactions is almost unintelligible, particularly as the diagrams are on different pages from the relevant text. The only positive value of this latter section derives from coupled reactions involving quartz, to which it might be usefully reduced. The third and fourth chapters contain the meat of the book, the quintessence of any course on metamorphic petrogenesis. Unfortunately, the author's bias towards low-pressure values of the $\mathrm{Al}_{2} \mathrm{SiO}_{5}$ triple point mars this and later sections, while some generalizations, such as that most solid-solid reactions characteristically have slopes of perhaps 15 to 20 bars/degree, are most misleading, and there is too little mention of fugacity or equilibrium pressure and of the importance of $f_{0_{3}}$. The author himself has pointed out that the ordinates in Figs. 4-9, 10 and 12 should be stated as weight per cent. The remaining chapters usefully relate the ACF-diagram type of treatment of facies to actual examples and to PT conditions of formation. The section on the low-temperature facies is particularly useful, but the granulite and eclogite facies sections are weak, it being particularly unfortunate to choose an $\mathrm{SiO}_{2}$-undersaturated rock to define the granulite facies boundary (page 325). The new idea of "transitional" facies is anathema to me, and I hope that I shall not see again the very odd slopes for the PT conditions of the high pressure facies series (Figs. 8-3, 4); further, the restriction of metamorphic conditions to $10 \mathrm{kbar}$ and $750^{\circ} \mathrm{C}$ seems unlikely. Nevertheless, it remains true that this is the best and most useful book there is on the subject. R. ST J. LAMBERT

\section{TRANSITIONAL RELATIVITY}

\section{Relativity and High Energy Physics}

By W. G. V. Rosser. (The Wykeham Science Series for Schools and Universities.) Pp. xi +147 . (Wykeham: London and Winchester, 1969.) 20s.

THIs book is the seventh in a very interesting serics. The aim of the series is to bridge the awkward gap between school and university teaching in science, and the publishors have hit upon the intriguing idea of supplementing the chief author, in each case an experienced teacher of science, with a second author who is a school master and who presumably works over the material to be sure that it is digestible. Such an attempt to bridge the gap is certainly commendable and in this case it is largely successful.

The book starts with a short chapter on Newtonian mechanies and the principle of relativity, and then there follows a chapter in which the variation of mass with velocity is developed from experimental information. In order that the experimental laws should hold in all inertial frames it is deduced that the Lorentz transformations must be the appropriate ones between these frames. In chapter three the author goes back to a more historical approach to special relativity, and sketches the path taken at the end of the nineteenth century.

In chapter four, yet another approach is given in which the constancy of the speed of light is taken for granted and radar methods of determining coordinates are used, as in Bondi's exposition and in Bohm's book. This 